\title{
Competitividade e restrição externa na Zona do Euro
}

\author{
ANDRÉ SANDER DINIZ \\ FREDERICO G. JAYME JR.*
}

Competitiveness and external constraint in the Eurozone. The recent debt crisis in Greece, Ireland and Portugal has exposed the fragility existing in the Eurozone for promoting development and economic convergence between the countries that have adopted the currency. Way beyond the fear of insolvency, what is observed is a growing disparity of the most-developed countries in comparison to the less-developed ones, with perverse consequences for the last ones. Once the nominal exchange rates are fixed, the divergent movements in relative prices and wages between the countries have led to totally distinct paths for the real exchange rates. Worsening the scenario, one can observe the incompleteness of the political union, the monetarist focus of the ECB and the lack of labor mobility between the countries, what distances from the argument stated by the theory and puts in jeopardize the future of the Monetary Union.

Keywords: exchange rate; currency area; inflation; current account; balance-of-payments constraints.

JEL Classification: E42; F33.

\section{INTRODUÇÃO}

O êxito da União Europeia - do ponto de vista econômico — deu sinais claros de fragilidade no momento em que as dívidas dos governos grego, irlandês e português, bem como seus déficits persistentes, revelaram-se para o mundo, geran-

\footnotetext{
"Economista - UFMG. E-mail: andrediniz89@yahoo.com.br; Professor do Departamento de Economia e do Cedeplar - UFMG e pesquisador do CNPq. E-mail: Gonzaga@cedeplar.ufmg.br. Submetido: 23/ agosto/2011; Aprovado: 13/dezembro/2011.
} 
do incertezas e apreensões na capacidade de manutenção do Euro. Esse contexto de incerteza gerou a primeira crise econômica de maiores proporções da União, provocando desvalorização do Euro, abalo nos mercados mundiais e colocando em xeque a constituição da União Econômica e Monetária baseada nos critérios de convergência econômica entre os países definidos no Tratado de Maastricht.

O presente trabalho tem como objetivo entender a dinâmica da crise da dívida na União Europeia, tendo como ponto de partida a Teoria de Áreas Monetárias Ótimas. A questão central é analisar a capacidade da União Monetária em promover o desenvolvimento conjunto de nações com estruturas produtivas distintas e as possibilidades de recuperação de choques assimétricos pelos países-membros principalmente os menos desenvolvidos - diante da perda de autonomia nas políticas monetária e cambial em um contexto de critérios de convergência econômica impostos pelos países mais desenvolvidos.

Mais do que isto, aqui se pretende contextualizar as dificuldades em garantir um sistema monetário unificado ante uma típica dinâmica centro-periferia entre países mais desenvolvidos vis-à-vis aqueles menos desenvolvidos na Europa. Neste contexto, a teoria tradicional de Áreas Monetárias Ótimas, que dá sustentação teórica ao modelo implementado na Europa, possui limitações flagrantes, que se manifestam com vigor em períodos de crises financeiras. De fato, nesses períodos as contradições de um sistema baseado fundamentalmente em critérios fiscais e monetários de convergência se apresentam de forma absolutamente clara. Como consequência, os países economicamente menos dinâmicos não são capazes de garantir a manutenção de um equilíbrio fiscal, menos pelos seus vícios e muito mais pela própria natureza de um desequilíbrio econômico, que é o que pretendemos mostrar neste trabalho.

Além desta introdução, este artigo é constituído de outras quatro seções. $\mathrm{Na}$ segunda seção são apresentados aspectos teóricos relacionados às Áreas Monetárias Ótimas, desde as abordagens clássicas da segunda metade do século XX até contribuições mais recentes de outros autores. A terceira seção trata de contextualizar a União Europeia num cenário de área monetária ótima, com uma breve exposição das bases da Zona do Euro e apresentação dos dados empíricos dos países-membros, para os períodos pré e pós-adesão. A quarta seção aborda os pontos considerados chave para o entendimento da crise do Euro: o direcionamento da atuação do Banco Central Europeu; as bases e a evolução da União em termos políticos; e a restrição externa e a competitividade como freio ao crescimento dos países. Finalmente, as considerações finais contêm algumas implicações da crise atual para o futuro da Zona do Euro, para a manutenção das bases atuais da União Monetária e para a possível adesão de novos países à mesma.

\section{A TEORIA DE ÁREAS MONETÁRIAS ÓTIMAS}

Uma área monetária é um conjunto de países ou regiões que optam por adotar um mesmo sistema monetário. Desde meados do século XX, há uma tentativa de 
se entender as vantagens e desvantagens de tal organização econômica para seus possíveis membros como forma de facilitar a busca por crescimento e equilíbrio macroeconômico.

Conforme Mundell (1961), a Teoria de Áreas Monetárias Ótimas aborda alternativas ao câmbio flutuante como fator para ajustar uma economia em desequilíbrio. Uma das alternativas é a depreciação do câmbio, que pode ser utilizada para eliminar déficits externos e desemprego ou, de forma alternativa, através da apreciação cambial, para eliminar superávits e possível inflação. As elucidações da teoria giram em torno da decisão de se estabelecer uma área monetária comum, de determinar sua dimensão, ou de deixar que todas as moedas de todas as regiões possam flutuar umas em relação às outras. Mundell (1961) afirma que a decisão de se utilizar taxas fixas ou flexíveis de câmbio deve se basear em moedas regionais, e não nacionais. No entanto, como "a moeda é principalmente um sinônimo de soberania nacional, e a real reorganização monetária só seria factível se acompanhada por grandes mudanças políticas" (Mundell, 1961, p. 661), cabe pensar qual seria o fator que mais aproximaria um país - ou um grupo deles - de uma área monetária ótima.

O mecanismo substituto da política cambial como fator de reequilíbrio da economia após choques adversos seria a mobilidade dos fatores de produção trabalho e capital - entre regiões. Caso a força de trabalho em excesso na região deficitária possa se mover para a região superavitária, onde há excesso de demanda por trabalho, o equilíbrio pode ser restabelecido sem que seja necessário utilizar a política cambial. Analogamente, caso a mobilidade de fatores seja alta entre países, estes poderiam formar uma união monetária. Alternativamente, a flexibilidade de salários e preços permite reajuste de preços relativos entre as regiões para reequilibrar suas economias.

Dividindo a economia em setores de bens comercializáveis e não comercializáveis, McKinnon (1963) afirma que, quanto maior é a participação dos setores exportadores, maior a tendência à flutuação nos níveis de preços internos quando o regime de câmbio é flexível. Uma área ótima é definida então com base na abertura comercial (razão entre produtos comercializáveis e não comercializáveis) e na mobilidade de fatores presente nos dois setores. Dessa forma, uma região com baixa mobilidade de fatores entre os setores da economia e grande abertura comercial poderia ser uma boa candidata a entrar em uma união monetária, uma vez que um choque adverso seria bastante perverso para sua economia, diante da impossibilidade de redirecionar demanda e oferta entre setores e do grande impacto sobre o nível interno de preços. A união monetária aparece como forma de reduzir o efeito negativo de instabilidade dos preços internos, fruto de variações cambiais, além de favorecer a promoção da mobilidade de fatores entre os países (regiões) constituintes dessa união monetária.

Mundell (1961) e McKinnon (1963) possuem argumentos distintos acerca da mobilidade de fatores. O primeiro considera a mobilidade o único fator capaz de substituir a flexibilidade cambial no combate a choques adversos e, portanto, determinante para se abrir mão da flutuação cambial em função de uma união mo- 
netária. O segundo observa que a mobilidade, exatamente por permitir ao país resistir a um choque adverso, o credita a não necessitar aderir a uma união monetária. Talvez essa diferença repouse no fato de McKinnon (1963) considerar a união monetária mais importante para conferir mobilidade de fatores entre países, sem dar muito peso à perda da possibilidade de desvalorização cambial.

Kenen (1969) acrescenta em sua contribuição o papel da política fiscal. Para ele a área de atuação da política fiscal deve coincidir com a área monetária ótima, de forma a otimizar a distribuição de recursos provenientes de impostos. Esse recurso seria utilizado para compensar diferenças regionais, aliviar recessões pontuais e criar programas especiais de auxílio técnico e financeiro.

Mais importante do que a definição de livre mobilidade de trabalho para constituir uma área monetária ótima é a diversidade do mix de produtos da região, ou seja, a quantidade de setores diferentes que um país possui em sua economia. A ideia é que uma economia diversificada tende a absorver melhor impactos de um choque de demanda externa, não precisando recorrer tanto a modificações nos seus termos de troca com o exterior, uma vez um grande número de setores favorece uma pauta de exportações diversificada, onde o boom de um setor pode compensar a desaceleração do outro, estabilizando a formação de capital doméstica. Ademais, a diversidade de setores favorece a mobilidade de trabalho, uma vez que cria maiores possibilidades de migração do trabalho para especialidades adjacentes. A conclusão é que taxas de câmbio fixas são mais apropriadas para países com economias diversificadas. Àqueles países de base produtiva altamente especializada e poucos recursos de política econômica recomenda-se o uso de câmbio flexível.

Segundo Carlin \& Soskice (2006), abrir mão da possibilidade de manipular a taxa de câmbio como resposta a um choque adverso é um custo que deve ser levado em conta na discussão de Áreas Monetárias Ótimas. É a partir desta questão que são desenvolvidos argumentos mais recentes da teoria de áreas monetárias.

Segundo os autores, os benefícios de uma Área Monetária Ótima relacionam-se a ganhos de eficiência econômica provenientes da eliminação das moedas nacionais e da adoção de uma moeda comum, quais sejam, (i) redução direta e/ou indireta nos custos de transação; (ii) redução da incerteza relacionada aos movimentos futuros na taxa de câmbio.

Os ganhos diretos advindos da eliminação de custos de transação se referem à eliminação das taxas sobre transações cambiais envolvendo moedas diferentes, como uma simples operação em casa de câmbio. Já os ganhos indiretos são mais difíceis de mensurar e se referem principalmente à restrição da prática de discriminação de preços entre os países. A possibilidade de discriminar preços está ligada às diferenças nos impostos e contribuições e nos custos administrativos de um país para outro. Juntamente com outras medidas gradualmente implementadas para a criação de um mercado comum, a adoção de moeda única tende a reduzir o escopo dos empresários para discriminar preços em diferentes mercados nacionais.

Os benefícios da redução da incerteza diante dos movimentos incertos da taxa de câmbio vão desde ganhos de bem-estar para a sociedade até ganhos de eficiência no mecanismo de preços. "Agentes econômicos baseiam suas decisões no que tange 
à produção, investimento e consumo na informação que o sistema de preços fornece a eles. Se esses preços se tornam mais incertos, a qualidade dessas decisões piora" (De Grauwe, 1997).

Por outro lado, a análise dos custos está ligada a aspectos macroeconômicos, girando em torno da impossibilidade de um país recorrer às políticas monetária e cambial - e com isso manejar taxas de juros, agregados monetários e taxas de câmbio - como forma de estabilizar a economia contra choques adversos quando entra em uma união monetária.

Um país que se encontre em uma união monetária em que a convergência econômico-institucional entre seus membros é ausente terá altos custos provenientes da maior dificuldade de seguir um caminho de crescimento sustentado e/ou de se recuperar de choques adversos. Fala-se aqui em convergência: (i) de preferências dos formuladores de política econômica, (ii) institucional, (iii) de crescimento entre os países. Este é um elemento central e que, aparentemente, demonstra problemas nos países menos desenvolvidos do bloco europeu.

As preferências dos formuladores de política econômica podem ser analisadas com base na política fiscal e na política monetária. A teoria-base para a análise das preferências dos formuladores de política monetária é o trade off entre desemprego e inflação explícito na modelagem da curva de Phillips em sua versão aceleracionista, proposta por Milton Friedman e Edmund Phelps, segundo a qual o custo de se abrir mão das desvalorizações cambiais e monetárias não é grande, visto que no longo prazo essas políticas são inúteis para combater o desemprego. No entanto, sejam válidos ou não os argumentos monetaristas, o fato é que perder a manipulação do câmbio e da moeda para estimular a economia se constitui em um custo para o país, pois essas políticas poderiam ser efetivas no curto prazo.

A política fiscal pode também ser encarada como um custo, caso não haja convergência entre os países. Países que aderem a uma união monetária com países de tradição anti-inflacionária - precisando também ter inflação baixa — enfrentarão perdas de bem-estar caso seus governos sejam deficitários, diante da necessidade de se aumentar impostos. De forma alternativa, uma união entre países com diferentes preferências de expansão fiscal pode gerar novos choques adversos, de acordo com o argumento de Kydland \& Prescott (1977), sendo desejável a aplicação de regras para a política fiscal.

O custo das divergências institucionais se refere ao mercado de trabalho. De Grauwe (1997) salienta que o poder e o grau de centralização dos sindicatos de um país podem afetar de forma diferente o perfil de recuperação de um país a choques assimétricos. Além disso, a ausência de coordenação institucional, por exemplo, na definição de salários, cria brechas para divergências de competitividade entre os países via custos de trabalho.

Finalmente, a ausência de convergência nas taxas de crescimento entre os países dificulta o equilíbrio de seus saldos comerciais via elasticidades-renda de importação e exportação. O descompasso entre crescimento e equilíbrio das contas externas pode ser então visto como um custo, caso não haja convergência de crescimento entre os países-membros de uma união monetária. 
Cabe, finalmente, esboçar a relação entre os custos e benefícios de uma união monetária e o grau de abertura econômica de um país. Segundo De Grauwe (1997), uma economia mais aberta tende a ganhar mais com uma união monetária, uma vez que o peso da eliminação de custos de transação é maior em países onde o comércio de bens e serviços com o exterior é mais intenso. Com uma maior interação com outros mercados e outras moedas, os agentes estarão mais sujeitos a erros de previsão e alocação de recursos com origem nas incertezas da flutuação cambial. Lane (2006) menciona ganhos para a Zona do Euro provenientes: (i) da reorganização dos mercados financeiros, que se tornaram mais líquidos e integrados, com destaque para a diminuição dos prêmios de risco envolvidos; (ii) da melhora da alocação de capital financeiro; e (iii) do aumento dos fluxos de investimento direto estrangeiro, beneficiando principalmente países periféricos e de renda menor.

A própria Comissão Europeia defende que a remoção de barreiras com o mercado comum reforçará a tendência à redução de choques assimétricos, uma vez que homogeneizaria as estruturas produtivas dos países. De Grauwe (1997) está de acordo com essa visão, corroborando-a com o argumento de que possa haver tendência à concentração e especialização produtivas entre regiões, mas não entre países, o que não prejudica a recuperação de choques assimétricos. Por outro lado, um país que exporte e/ou importe grande parcela do seu produto pode ser mais efetivo em estimular a economia com uma desvalorização, mas ao mesmo tempo está mais sujeito a variações frequentes no nível de preços. Considerando que sucessivas desvalorizações são desaconselhadas, bem como a instabilidade de preços é vista como custo, a união monetária é positiva para um país aberto, que não paga um preço alto por abrir mão de sua política cambial.

É consenso que um nível maior de abertura tende a facilitar a entrada de um país numa união monetária, o que, por sua vez, favorece a integração comercial com os outros membros da união: quanto maior a abertura de um país, maiores os benefícios e menores os custos de adesão a uma união monetária. As correntes teóricas divergem quanto ao grau ótimo de abertura, de acordo com a importância conferida à política cambial. Monetaristas consideram um nível ótimo de abertura necessário menor que keynesianos, uma vez que o custo de se abrir mão da política monetária para os últimos é maior que para os primeiros, o que exigiria maior abertura econômica para compensar.

Sobre a questão da mobilidade de fatores e da rigidez de preços e salários, central na discussão dos autores clássicos, percebe-se que uma redução da rigidez de preços e salários ou um aumento da mobilidade de trabalho reduzem os custos de uma união, tornando-a mais atrativa. Embora a mobilidade de capital na União Europeia seja alta em função do mercado comum, a mobilidade da força de trabalho ainda é muito baixa, provavelmente em função de diferenças culturais e linguísticas entre os países. Com efeito, a mobilidade da força de trabalho como fator necessário para a união monetária vem sendo enfatizada desde o artigo inicial de Mundell (1961). 


\section{A UNIÃO MONETÁRIA EUROPEIA}

\section{Histórico e critérios de convergência}

O embrião da União Europeia encontra-se no imediato pós-guerra, com a aproximação dos países europeus para a manutenção da paz, fortalecimento e reconstrução da Europa que estava destruída pela Segunda Guerra Mundial. Importantes marcos na constituição da união econômica e monetária foram: (i) a constituição da Comunidade Europeia do Carvão e do Aço (1951); (ii) a assinatura do Tratado de Roma (1957), que deu ênfase à unificação pela via econômica, com a instituição da Comunidade Econômica Europeia (CEE); (iii) a criação do ERM (Exchange Rate Mechanism) e a posterior entrada em vigor do Sistema Monetário Europeu (1979), que contribuiu para estabilização inflacionária dos países-membros, cujas taxas de câmbio foram fixadas em relação ao Deutsche Mark.

A assinatura do Single European Act (1986) deu passo crucial para a liberalização dos fluxos de bens, serviços e fatores de produção. Em 1989 é proposta a União Monetária Europeia (UME), complemento necessário para ampliar a integração do mercado europeu, inclusive de capitais, evitando ataques especulativos e realinhamentos monetários que eram comuns no SME. A criação de um Banco Central Europeu consideraria mais os problemas individuais de cada país e receberia sugestões de todos para realizar política monetária, em vez de somente seguir a linha restrita do Bundesbank. Em 1992 é assinado o Tratado de Maastricht — ou Tratado da União Europeia - que criou formalmente uma União Europeia, em substituição à CEE, induzindo novas formas de cooperação entre os países-membros, em domínios como defesa, justiça e assuntos internos. O maior impacto do tratado foi, no entanto, a definição das bases para a criação da união econômica e monetária (UEM). Além de estabelecer regras para a adoção da moeda comum, foi estipulada para 1993 a criação efetiva do mercado comum, que garantiu a livre circulação de pessoas, capitais, mercadorias e serviços entre os países da Comunidade.

O Tratado de Maastricht estabeleceu critérios de convergência nominal macroeconômica em algumas áreas, para que os países candidatos pudessem ter sua adesão à UME efetivada. Um país só poderia entrar na união caso se enquadrasse nos seguintes pressupostos: taxa de inflação máxima de 1,5 ponto percentual em relação à média dos três países com menor inflação; taxa de juros máxima de 2 p.p. também em relação à média dos três países menos inflacionários; não ter promovido desvalorizações cambiais nos dois anos precedentes à adesão; déficit público nominal máximo de $3 \%$ do PIB; dívida pública máxima nominal de $60 \%$ do PIB. Para os últimos dois critérios aceitava-se a entrada do país caso o déficit e a dívida estivessem se reduzindo progressivamente e se encontrassem em nível bastante próximo ao de referência.

O Pacto de Estabilidade e Crescimento de 1997 foi o último estágio antes do 
alcance do terceiro - e definitivo - passo na integração econômica, qual seja, a adoção da moeda comum, que passou a ser meio de conta em 1999 e a circular em 2002. Para tal as taxas de câmbio entre as moedas nacionais dos países foram fixadas e entrou em operação o Banco Central Europeu, que assumiu a política monetária da união e lançou a nova moeda. O Pacto prevê penalidades para os países que não se mantiverem dentro dos critérios estipulados para a convergência econômica.

\section{Evidência empírica na Zona do Euro}

A análise empírica busca avaliar os efeitos da união monetária sobre as economias europeias, com enfoque em três questões principais: (i) a trajetória de convergência das variáveis de Maastricht; (ii) a evolução do nível da atividade econômica e das contas externas; (iii) a presença dos fatores desejáveis para uma união monetária. ${ }^{1}$

\subsection{Convergência econômica sob critérios de Maastricht}

Os Gráficos 1 a 4 mostram a evolução das variáveis de referência para a adesão à Zona do Euro, segundo os critérios de Maastricht - inflação, taxa de juros, resultado nominal do Setor Público e Dívida Pública, os dois últimos em percentual do PIB. De forma geral, observa-se que os membros do Euro conseguiram se manter dentro, ou bem próximos, dos limites estipuladas pelos critérios acima expostos, havendo diminuição do gap entre esses dois grupos no que tange a essas variáveis, o que pode ser concebido como uma trajetória de convergência entre suas economias e vai ao encontro dos argumentos teóricos da Área Monetária Ótima. O atendimento aos critérios foi, contudo, muito mais fácil para os países mais desenvolvidos do bloco (EU16RICOS), que já apresentavam valores de referência históricos menores - e consequentemente mais próximos das metas - do que os países menos desenvolvidos (EUPIIGS).

\footnotetext{
${ }^{1}$ Os dados foram trabalhados a partir das bases do Eurostat, escritório de estatísticas da União Europeia. Utilizou-se a divisão dos países em dois grupos, para efeitos de comparação. O primeiro constitui-se de Alemanha, França, Áustria, Bélgica e Holanda e foi denominado "EU16 ricos". O segundo constitui-se de Portugal, Itália, Irlanda, Grécia e Espanha, e foi denominado "EU16 piigs". O período da análise se estende de 1995 a 2007. Algumas variáveis não têm dados para o período completo. Para efeitos de análise de médias, foram considerados os períodos 1995-1999 e 2000-2007, respectivamente antes e depois da criação do Euro. Embora o Euro como moeda circulante só tenha entrado em vigor em 2002, já em 1999 foram congeladas todas as taxas de câmbio dos países-membros, bem como suas transações passaram a ser realizadas com base no Euro como unidade de conta.
} 


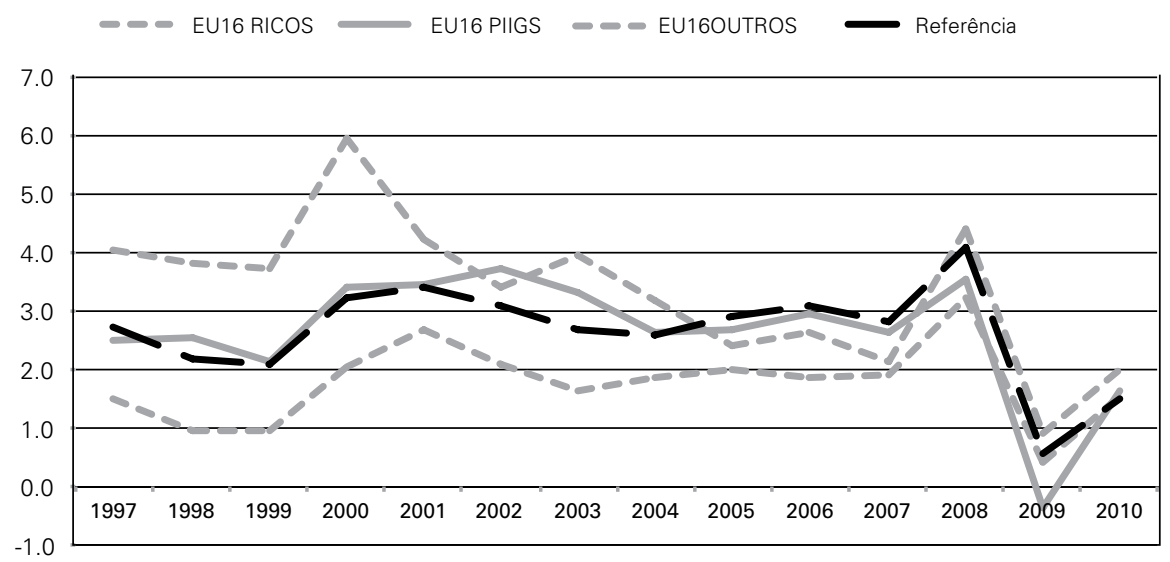

Observando-se o Gráfico 1, percebe-se um aumento da inflação média dos dois grupos no período 2000-2007, possivelmente devido ao reflexo da adesão de novos países tradicionalmente mais inflacionários ao Euro. É possível notar que os "piigs" só conseguem ficar de fato abaixo da meta a partir de 2004, permanecendo, entretanto, com um desvio de aproximadamente 1,5 p.p. para os "ricos". Os países que mais pressionam para baixo a média deste grupo — determinando assim a referência da meta - são a Alemanha e a Áustria, enquanto a Grécia e a Espanha pressionam a média para cima, dificultando a manutenção dos índices dentro do parâmetro.

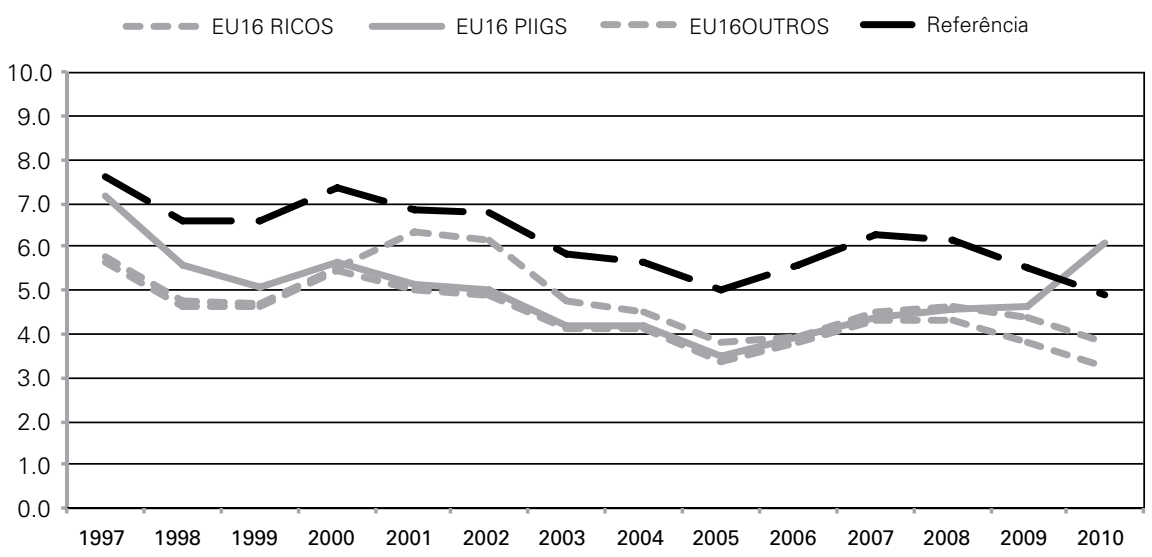

A taxa de juros (Gráfico 2), por sua vez, apresenta trajetória de convergência quase perfeita entre os dois grupos de países, permanecendo sempre abaixo da meta.

Com relação ao resultado nominal do setor público (Gráfico 3), observa-se que todos os membros da Zona do Euro foram eficazes em manter seu déficit 
abaixo do teto de $3 \%$ do PIB. No entanto, nota-se piora no déficit público dos dois grupos logo após a adoção do Euro, só voltando a se reduzir a partir de 2004.

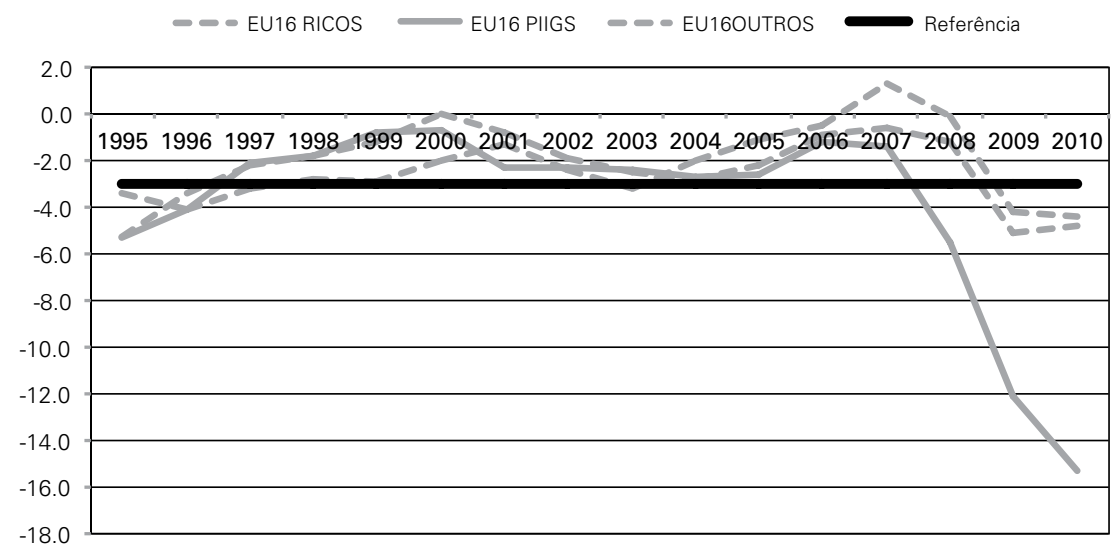

Finalmente o Gráfico 4 apresenta a trajetória da dívida pública, única variável que não aparece, em média, dentro dos níveis de convergência de referência em nenhum momento. Dados de 1999 mostram que somente Alemanha, França, Irlanda e Portugal conseguiram se manter dentro do limite de $60 \%$ de dívida em relação ao PIB. Os outros países, no entanto, mostraram reduções significativas em suas médias históricas até 1999, e esse comprometimento possibilitou sua entrada no Euro. Embora em constante declínio até 2007, reflexo do controle orçamentário dos governos, a dívida pública de $60 \%$ nunca foi alcançada.

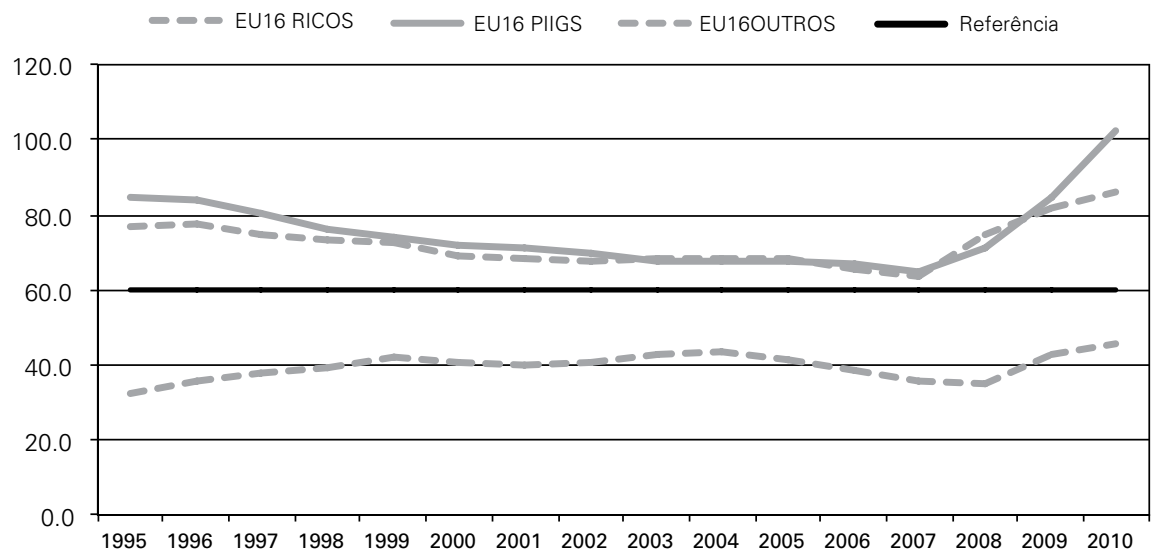

\subsection{Atividade econômica e contas externas}

Embora os países do Euro tenham alcançado em grande medida a convergência esperada, o processo foi conseguido com custos para o crescimento e com efeitos sobre restrição externa em muitos países, principalmente os menos desenvolvidos, como será discutido adiante. A Tabela 1 destaca a desaceleração do cres- 
cimento do PIB para a Zona do Euro como um todo após a adoção da moeda. Essa desaceleração é mais evidente para os "piigs", que reduzem seu crescimento em média $25 \%$ de um período para o outro, mantendo, porém, taxas mais altas que a média dos países "ricos". O desemprego caiu em média para todos os países, à exceção de Portugal, onde a taxa aumentou $30 \%$ na comparação dos dois períodos. Os "piigs" reduziram suas taxas de desemprego mais acentuadamente que os "ricos", porém estes ainda têm níveis de ocupação um ponto percentual mais altos, em média, do que aqueles.

Tabela 1: Crescimento econômico e resultado em transações correntes antes e depois da adoção do Euro

\begin{tabular}{|l|c|c|c|c|c|c|}
\hline \multirow{2}{*}{} & \multicolumn{2}{|c|}{ Cresc. PIB (\%) } & \multicolumn{2}{c|}{ Desemprego (\%) } & \multicolumn{2}{c|}{ SaldoTC (\%PIB) } \\
\cline { 2 - 7 } & $\begin{array}{c}\text { Média } \\
\text { 1996-1999 }\end{array}$ & $\begin{array}{c}\text { Média } \\
\text { 2000-2007 }\end{array}$ & $\begin{array}{c}\text { Média } \\
1998-1999\end{array}$ & $\begin{array}{c}\text { Média } \\
2000-2007\end{array}$ & $\begin{array}{c}\text { Média } \\
1995-1999\end{array}$ & $\begin{array}{c}\text { Média } \\
2000-2007\end{array}$ \\
\hline Alemanha & 1.7 & 1.5 & 9.4 & 9.3 & 1.1 & 4.3 \\
França & 2.5 & 2.1 & 12.1 & 8.9 & 2.3 & 0.1 \\
Bélgica & 2.6 & 2.2 & 9.0 & 7.4 & 3.7 & 4.3 \\
Holanda & 4.1 & 2.2 & 4.0 & 3.4 & 5.0 & 7.0 \\
Áustria & 2.8 & 2.4 & 5.1 & 4.8 & -0.1 & 3.9 \\
\hline EU “ricos" & 2.7 & 2.1 & 7.9 & 6.8 & 2.4 & 3.9 \\
\hline Portugal & 4.3 & 1.5 & 4.7 & 6.1 & -8.8 & -8.9 \\
Irlanda & 9.7 & 6.0 & 6.8 & 4.3 & 12.6 & 13.7 \\
Espanha & 3.9 & 3.6 & 17.1 & 10.5 & -0.2 & -4.1 \\
Grécia & 3.2 & 4.2 & 11.4 & 9.8 & $*$ & -11.7 \\
Itália & 1.5 & 1.5 & 11.9 & 8.4 & 3.4 & 0.4 \\
\hline EU “piigs" & 4.5 & 3.4 & 10.4 & 7.8 & 1.8 & -2.1 \\
\hline Zona do Euro & 3.6 & 2.7 & 9.2 & 7.3 & 2.1 & 0.9 \\
\hline
\end{tabular}

* Não há dados para o período

Fonte: Elaboração própria a partir de dados do Eurostat.

Destaque é dado nesta seção para o saldo em transações correntes do Balanço de Pagamentos. É evidente aqui a discrepância da trajetória dos países "ricos" e dos "piigs", como mostra o Gráfico 5. Enquanto o primeiro grupo vê seu saldo em conta-corrente acumular superávits crescentes após a adoção do Euro, clara trajetória descendente atravessa o segundo grupo, cujo saldo de transações correntes passa de um leve superávit antes da adoção do Euro para sucessivos déficits a partir dos anos 2000. A Irlanda é a exceção, pois apresenta fortes superávits externos da ordem de $15 \%$ para todo o período, o que pressiona a média para cima. $\mathrm{Na}$ realidade Portugal, Espanha e Grécia apresentam grandes déficits externos, muito acima da média do grupo, sugerindo que seu crescimento tenha sido em grande medida baseado em aumento da restrição externa. A Itália passa de superávits anteriores à adoção do Euro para leves déficits atualmente. 


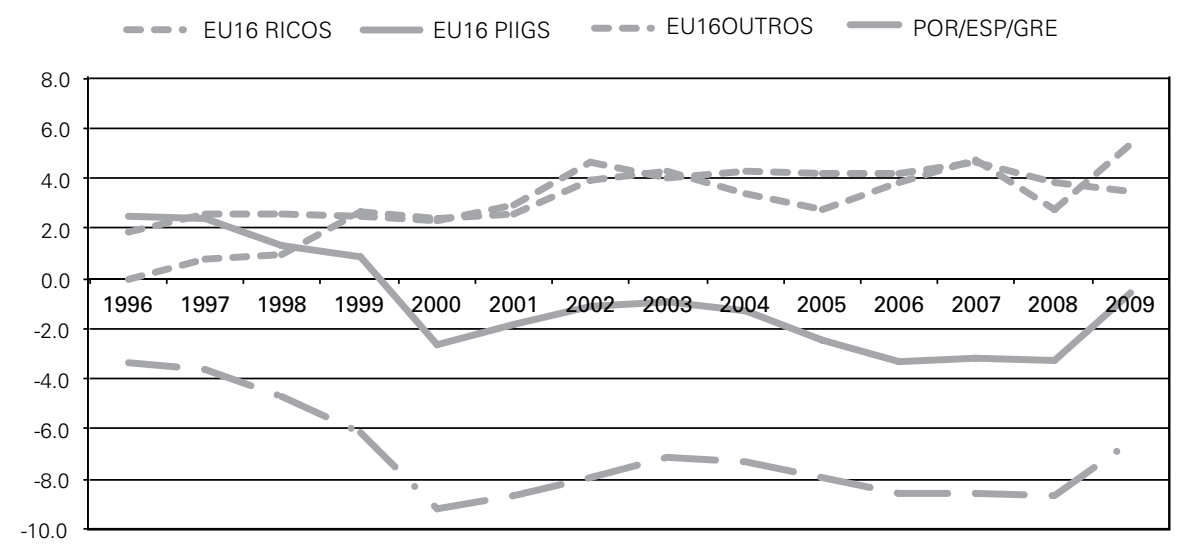

\subsection{Grau de abertura e produtividade na Zona do Euro}

A teoria de áreas monetárias ótimas frisa a importância da integração dos fluxos de mercadorias e pessoas para aliviar choques adversos. Como forma de medir a presença desses fatores na UME foram analisados a evolução do grau de abertura das economias e o percentual de comércio realizado com a Zona do Euro em cada país.

É possível observar a mobilidade da força de trabalho pela correlação entre crescimento do PIB (defasado em um ano) e a variação da emigração da população, para avaliar se em momentos de recessão há maior saída da força de trabalho. Além de haver poucos dados, a correlação não foi significante para nenhum país, mostrando que é difícil estabelecer qualquer conclusão sobre o comportamento dessas duas variáveis, provavelmente corroborando o fato de que a mobilidade de mão de obra ainda é muito pequena entre os países da Zona do Euro, principalmente em função de diversidades culturais e linguísticas.

A Tabela 2 retrata que o grau de abertura do grupo dos países "ricos", com a exceção da França, elevou-se entre 2000 e 2008. Em contraste, o grupo dos "piigs", com a exceção de Portugal, apresentou retração na abertura para o período.

A Tabela 3, por seu turno, denota quase $70 \%$ das exportações (importações) dos países da Zona do Euro sendo destinadas (provenientes) de parceiros da União Europeia, indicando alto grau de integração entre essas economias, fator importante de acordo com a literatura sobre Áreas Monetárias Ótimas. A satisfatória integração comercial com a União Europeia para ambos os grupos é reflexo do livre mercado, facilitando transações de mercadorias e serviços entre os países, com ganhos potenciais de comércio no bloco. Por outro lado, uma parceria comercial majoritária com países europeus pode gerar dependência excessiva desses mercados.

O Gráfico 6 apresenta uma estimativa das taxas de câmbio real dos países, baseado na evolução da produtividade e na inflação doméstica entre 1999 e 2007 para alguns países selecionados da União Europeia. Nesse caso foi usado como 
Tabela 2: Evolução do grau de abertura da economia

\begin{tabular}{l|c|c|c|}
\hline \multirow{2}{*}{} & \multicolumn{3}{|c|}{ Grau de abertura } \\
\cline { 2 - 4 } & $\mathbf{2 0 0 0}$ & $\mathbf{2 0 0 8}$ & Variação \\
\hline Alemanha & $55 \%$ & $72 \%$ & $31 \%$ \\
França & $50 \%$ & $47 \%$ & $-6 \%$ \\
Itália & $44 \%$ & $48 \%$ & $9 \%$ \\
Bélgica & $157 \%$ & $185 \%$ & $18 \%$ \\
Holanda & $117 \%$ & $139 \%$ & $19 \%$ \\
Áustria & $73 \%$ & $88 \%$ & $21 \%$ \\
Portugal & $55 \%$ & $58 \%$ & $5 \%$ \\
Irlanda & $132 \%$ & $79 \%$ & $-40 \%$ \\
Espanha & $47 \%$ & $44 \%$ & $-6 \%$ \\
Grécia & $36 \%$ & $33 \%$ & $-8 \%$ \\
\hline
\end{tabular}

Fonte: Elaboracão própria a partir de dados do Eurostat.
Tabela 3: Comércio exterior com parceiros da União Europeia

\begin{tabular}{l|c|c}
\hline \multirow{2}{*}{} & \multicolumn{2}{|c}{ \% de X e M com EU / Total } \\
\cline { 2 - 3 } & Importação & Exportação \\
\hline Alemanha & $65 \%$ & $63 \%$ \\
França & $69 \%$ & $62 \%$ \\
Itália & $57 \%$ & $57 \%$ \\
Bélgica & $71 \%$ & $76 \%$ \\
Holanda & $49 \%$ & $77 \%$ \\
Áustria & $78 \%$ & $72 \%$ \\
Portugal & $78 \%$ & $75 \%$ \\
Irlanda & $66 \%$ & $61 \%$ \\
Espanha & $61 \%$ & $69 \%$ \\
Grécia & $64 \%$ & $63 \%$ \\
\hline Fonte: Elaboracão própria a partir de dados do Eurostat.
\end{tabular}

deflator um índice de custos de trabalho. O que se observa é um grande desvio entre os países, provocado por preços relativos do trabalho com evolução divergente entre eles, o que afeta a competitividade. Com esta estimativa, a evolução da produtividade alemã impacta num câmbio real mais desvalorizado, gerando ganhos de competitividade indiretos do país dentro da União Europeia. Embora o câmbio nominal seja fixo, esses ganhos indiretos de competitividade têm o efeito de uma desvalorização real da taxa de câmbio, o que se relaciona, em parte, com o resultado positivo em transações correntes vis-à-vis os países menos desenvolvidos da União Europeia. ${ }^{2}$ Pode-se perceber que Irlanda, Espanha, Itália, Portugal e Grécia foram os países onde o câmbio real ficou mais valorizado, exatamente por serem países menos desenvolvidos e com menor inserção nas exportações mundiais se comparados com a Alemanha. Com efeito, a impossibilidade de desvalorizar o câmbio impede que esses países garantam maior competitividade no mercado internacional, minorando os efeitos deletérios que o estoque da dívida gera sobre a estabilidade desses países.

Dessa forma, houve perda de competitividade de quase $30 \%$ entre os extremos (Irlanda em relação à Alemanha). Percebe-se que se por um lado a Irlanda não teve saldos negativos em transações correntes, por outro foi o país que apresentou perda de competitividade mais progressiva ante os outros membros da Zona do Euro. Os dados mostram, portanto, que a flexibilidade de ajuste dos preços e salários é bastante reduzida, em oposição ao que a literatura aborda como ideal, o que prejudica a possibilidade de ajustes nos preços relativos dos fatores como forma de atingir o equilíbrio comercial entre os países.

\footnotetext{
${ }^{2}$ Obviamente a evolução da produtividade da mão de obra na Alemanha se explica também pelo seu desenvolvimento tecnológico em relação a países como Portugal, Espanha, Grécia e Irlanda.
} 


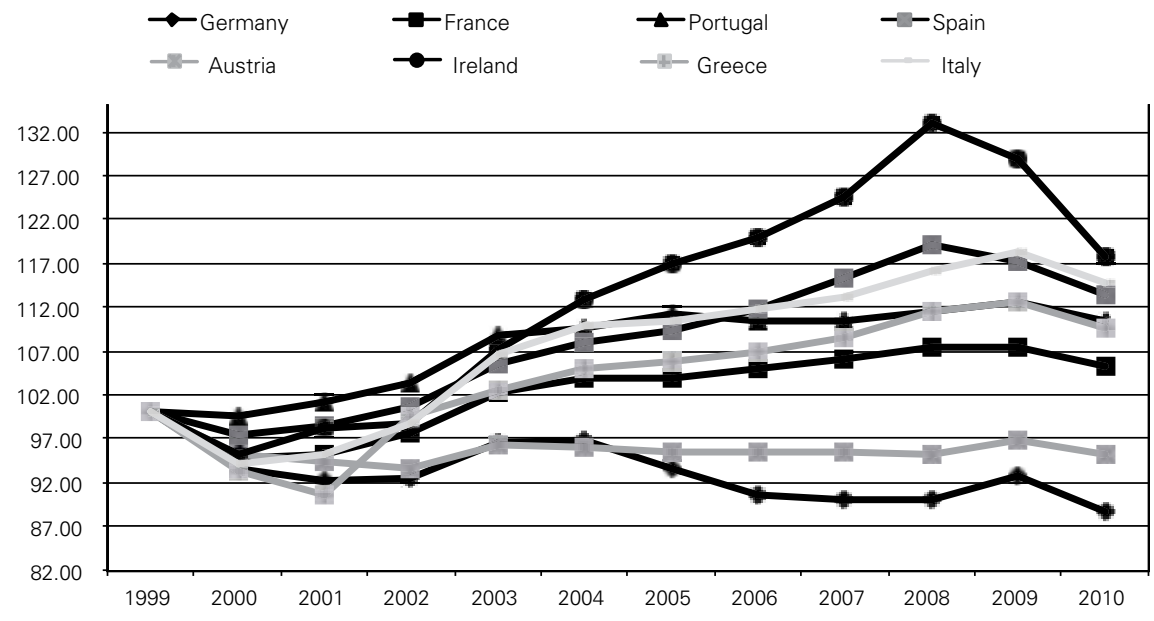

\section{CONSIDERAÇÕES AO MODELO DA UNIÃO MONETÁRIA EUROPEIA}

\section{Dívida pública e a crise do Euro}

$\mathrm{Na}$ seção anterior foi possível perceber que a primeira década da União Europeia foi marcada por convergência controversa nos ciclos econômicos dos países. Os critérios de convergência inflacionária e orçamentária de Maastricht foram atingidos pela maioria dos membros até 2008 , mas ao custo de crescimento moderado e piora dos saldos de transações correntes para os países menos desenvolvidos. Ademais, observou-se que a evolução do grau de abertura econômica e principalmente da mobilidade dos fatores de produção e do ajuste de preços relativos não esteve de acordo como o que seria considerado "ótimo" pela teoria de Áreas Monetárias. Em relação a este último, observou-se a preocupante divergência na trajetória das taxas de câmbio real entre os países.

A crise de 2008 gerou recessão, desemprego e desconfiança nos mercados internacionais. Na União Europeia significou também ultrapassagem dos limites de referência de $3 \%$ de déficit público em vários países, como tentativa de manter a demanda aquecida, reduzindo o impacto negativo sobre o produto e, principalmente, para salvar grandes bancos privados da falência. Apesar de terem reduzido seus déficits públicos progressivamente para adotar o Euro, países como Grécia e Portugal jamais conseguiram se enquadrar nos limites de referência de $3 \%$, tendo perdido totalmente o controle com a crise do subprime. Considerando ainda problemas em relação à arrecadação tributária nesses países, o resultado é um orçamento público constante e progressivamente deficitário, com reflexos sobre a dívida pública, que também fugiu da trajetória de convergência a partir de 2009.

Tudo isso gera perdas de credibilidade em relação a essas economias, com re- 
flexos sobre a Zona do Euro como um todo. A crescente dívida pública coloca os governos reféns de empréstimos mais onerosos para rolagem das mesmas. A alternativa encontrada na proposição de planos para recuperação dos déficits, com cortes drásticos em gastos públicos, congelamento de salários e aposentadorias, fim de benefícios e aumento de impostos, obviamente gerou greves e protestos. Não obstante esta estratégia de ajuste seja reconhecidamente insatisfatória, haja vista os exemplos históricos da crise da dívida nos anos 1980, ou mesmo a crise cambial Argentina de 2000, o FMI e os outros países da União Europeia acabaram por garantir pacotes bilionários, contrariando a ideia de no bail-out prevista nos critérios de convergência.

Nesse sentido, as seções seguintes apresentam algumas causas para a incapacidade desses países de se desenvolverem plenamente dentro da união monetária, contexto que levou à eclosão da crise descrita acima e dos temores quanto à credibilidade econômica desses países.

\section{Questões estruturais da Zona do Euro: o BCE e a união política}

O Banco Central Europeu é excessivamente preocupado com o controle de preços, prejudicando as perspectivas de crescimento econômico pelo seu conservadorismo excessivo, com raízes no modelo de atuação do Bundesbank alemão. Tal orientação foi a única forma de garantir que a Alemanha - economia mais forte do Euro - aceitasse se unir monetariamente a países de tendências mais inflacionárias do que as suas.

O resultado é um Banco Central Europeu que, segundo Ferrari Filho et al. (2003), acredita que "a inflação é um fenômeno monetário e pode ser controlada através de política monetária” baseada em regras conservadoras. ${ }^{3} \mathrm{~A}$ crítica está no fato de a política monetária do BCE se alinhar com a ideia de NAIRU (taxa de desemprego não aceleradora da inflação). Nesse sentido, o BCE atua exclusivamente no controle da inflação, sem preocupações com a evolução do desemprego. A orientação do BCE de controle da inflação explica, por exemplo, a política monetária conservadora de combate anticrise, quando a redução das taxas de juros para estimular a economia foi muito menor do que a realizada pelo FED norte-americano e por outros Bancos Centrais de países importantes. Caso acompanhasse os outros Bancos Centrais, o impacto recessivo sobre a Zona do Euro poderia ter sido menor.

Outra crítica se refere à falha na realização de outras atribuições, em função do foco excessivo nos preços. O BCE tem em seu corpo de funções, além da política monetária strictu sensu, conduzir operações cambiais, deter e gerir as reservas oficiais dos países-membros, supervisionar bancos e instituições de crédito, entre outros. Como exemplo, De Grauwe (2009) afirma que o BCE falhou em controlar

\footnotetext{
${ }^{3}$ Importante ressaltar que esta não é uma prerrogativa apenas do BCE, uma vez que dezenas de Bancos Centrais mundo afora utilizam a mesma estratégia.
} 
o grande aumento de crédito pelos bancos e o controle de possíveis bolhas especulativas - mais frequentes com a liberalização, a desregulamentação do sistema financeiro e a diversificação de ativos. A supervisão dos bancos também continuou sob tutela dos bancos e reguladores nacionais, ao invés de ser passada para o BCE, embora a política monetária tenha sido centralizada ao nível europeu. $\mathrm{O}$ autor defende a utilização de instrumentos para controlar o crédito dos bancos, como o requerimento de reserva mínima para os bancos comerciais.

Um outro aspecto que vem à tona é a profundidade e a eficácia da união em termos políticos. O arranjo institucional europeu ${ }^{4}$ é complexo e vem sendo desenvolvido ao longo das últimas décadas, mesmo antes do Tratado de Maastricht. Embora bem desenhado e bastante representativo dos interesses em todos os âmbitos, com várias instituições democráticas e rotatividade da presidência entre os países, parece haver um descompasso entre a integração política e a política econômica ao nível da união, com reflexos negativos para os países.

Se o impacto do Euro é deflacionário, isso está ligado ao perfil de política monetária do BCE discutido na seção anterior e aos critérios de convergência impostos aos países. Por outro lado, o impacto desestabilizador estaria ligado à falta de integração política e de coordenação institucional na Zona do Euro. A falha da integração política se dá no fato do reduzido número de políticas comuns de fomento econômico, que permitam uma aproximação dos ciclos econômicos entre os países-membros, facilitando assim a coordenação de política econômica, a atuação em bloco e minimizando os impactos díspares causados por flutuações econômicas em cada país individualmente. Talvez essa falha resida no fato de que os políticos nacionais são totalmente responsáveis pelo desemprego e pelas recessões, enquanto os instrumentos-chave para lidar com o problema não estão ao alcance deles. Em outras palavras, devido à política monetária conservadora do BCE e à limitação para exercer política fiscal, surge um entrave para o país individualmente promover crescimento e emprego. A coordenação política ao nível europeu não estaria, dessa forma, em sintonia com as necessidades de cada país.

Mas o ponto principal da discussão é "o limitado número de políticas de âmbito europeu em relação a acordos salariais, previdenciários, orçamentários, além de políticas sociais e de crédito" (De Grauwe, 2010), o que torna os ciclos econômicos dos países divergentes e até conflitantes em alguns pontos. Nesse sentido, Ferrari Filho et al. (2003) propõem a criação de um orçamento comum como fator estabilizador dos ciclos de negócios e elemento redistributivo importante, afirmando que não há nenhum mecanismo de política fiscal no âmbito europeu que atue como estabilizador automático. $\mathrm{O}$ argumento não é novo, e está presente desde

\footnotetext{
${ }^{4}$ A união política dentro da União Europeia tem como principais pilares o Parlamento Europeu, a Comissão Europeia e o Conselho Europeu, criados nos anos 1950 para representar, respectivamente, os cidadãos, os Estados-membros e a União Europeia no seu todo. No campo econômico, o Banco Europeu de Investimento concede empréstimos aos projetos de interesse europeu, principalmente em infraestrutura e meio ambiente nos países menos favorecidos. O Fundo Europeu de Investimento dá apoio às pequenas empresas e o Banco Central Europeu dita o ritmo da política monetária.
} 
Kenen (1969), que demonstra a importância da política fiscal coincidir com a área monetária, através da distribuição otimizada das receitas de impostos entre os países para aliviar divergências regionais. A ideia é ter um fundo de auxílio mútuo entre os países, constituído com recursos provenientes de países superavitários (ou em crescimento acelerado) e destinado a países deficitários (ou em recessão). De Grauwe (1997) mostra a importância de controlar os déficits como forma de criar esse fundo de transferências, criticando, por outro lado, a excessiva restrição fiscal e as multas previstas no Pacto de Estabilidade e Crescimento caso o país seja constantemente deficitário. Segundo o autor deve haver um mecanismo de transferências temporárias que não permita aos países relaxar a política fiscal de forma a incorrer sempre em déficits tornando-se sempre receptor, o que causaria insatisfação por parte dos países doadores. A intenção é que a coordenação institucional pelos órgãos europeus imponha responsabilidade sobre os países, para que as transferências sejam temporárias e nenhum país permaneça sempre como doador (ou receptor), mas que se ajudem ao longo do tempo para reduzir o grau de flutuação das economias como um todo.

Ferrari Filho et al. (2003) entendem ainda que devam ser incluídos programas significativos de taxação e convergência das instituições do mercado de trabalho ao nível da União Europeia, concernente a salários e seguridade social, cuja importância já foi demonstrada e se revela central na análise dos desvios de câmbio real entre os países.

Essa questão, embora tangente à união política, implica outra discussão que será desenvolvida na próxima seção e é central para a conclusão deste trabalho, centrada na competitividade e na convergência econômica em cenário de câmbio fixo, que têm efeitos de limitação sobre a política fiscal e de restrição externa ao crescimento.

\section{Câmbio Real, competitividade e restrição externa: uma proposta de entendimento da crise}

O principal entrave ao desenvolvimento dos países mais frágeis do Euro encontra-se na incapacidade da UME em superar as diferenças estruturais entre as suas nações-membros e convergir seus ciclos econômicos. Até o momento, e a crise demonstra isto de forma cabal, não houve um esforço conjunto do bloco em promover reformas estruturais que conferissem condições equitativas de desenvolvimento a todos os países, sob uma dinâmica econômica balizada por fatores que por si sós já limitam a atuação nacional no campo das políticas econômicas. Esses fatores são a âncora cambial no Euro, a política monetária centralizada e a restrição fiscal prevista no tratado da União Europeia.

Colocar países totalmente diferentes (em termos produtivos, tecnológicos, estruturais, entre outros) sob uma união monetária implica impor para todos eles um modelo de desenvolvimento mais ou menos definido e limitado pela estrutura institucional europeia. Fica muito mais natural atender aos critérios de convergência 
e evitar o aparecimento de déficits públicos e/ou externos caso um país tenha estrutura industrial diversificada e um histórico de baixa inflação.

Os dados apresentados na seção anterior apontam para uma tendência de dispersão do câmbio real entre os países-membros e de piora progressiva nos déficits em transações correntes nos países denominados "piigs", enquanto os países do grupo mais desenvolvido apresentam saldo externo crescentemente superavitário. Déficits em transações correntes não raro conduzem a aumento do passivo externo para financiar o crescimento do país. A dependência de capital externo pode ser um fator limitante ao crescimento, uma vez que, além do serviço da dívida externa, o país fica à mercê dos fluxos de capital internacionais, que podem se tornar escassos e são constantemente fruto de especulação, deixando a economia altamente vulnerável a flutuações externas. Thirlwall e Hussein (1982) já demonstravam que o fluxo de capitais para países deficitários contribuía para aliviar a restrição externa e permitia que países crescessem no curto prazo acima da taxa compatível com o equilíbrio do balanço de pagamentos. Moreno Brid (1999) e Barbosa-Filho (2001) demonstraram o efeito do passivo externo nesse contexto.

O que os dados demonstram é que o principal fator gerador de restrição externa não é o déficit público, mas a perda progressiva de competitividade em cenário de câmbio fixo, consoante com a literatura de restrição externa à la Thirlwall, contrastando com a visão dos déficits gêmeos, que encontra uma relação direta entre os déficits fiscais e os déficits externos.

A fraqueza da causalidade entre déficit público e déficit em conta-corrente é apontada por Resende (2009). Sem entrar no mérito da compensação do desequilíbrio fiscal via efeito crowding out ou Equivalência Ricardiana - situação que não afetaria a conta-corrente — há que se considerar que a dinâmica da poupança nacional está muito mais ligada ao efeito competitividade no comércio exterior para o saldo externo do que propriamente uma expansão fiscal. Por competitividade entende-se a dinâmica de preços relativos e, necessariamente, a taxa de câmbio real, bem como a competitividade não preço. "Ambos, a competitividade real e o comportamento do gasto-poupança (incluindo políticas fiscais), juntos determinam o balanço comercial” (Blecker, 1992). Além disso, podem ser incluídos na análise outros fatores, tais como a demanda externa, o perfil de gasto dos governos de outros países e a política monetária, que tornam o argumento de déficits gêmeos ainda mais frágil. Para finalizar, "no médio/longo prazo a produção doméstica potencial de bens de investimento pode ser ampliada por meio do progresso técnico, não havendo problema [...] de insuficiência de poupança real” (Resende, 2009), o que coloca importância sobre o desenvolvimento tecnológico dos países e a complexidade de suas estruturas industriais.

Dessa forma, corrobora-se a ideia de que o déficit em conta-corrente do grupo menos desenvolvido do Euro se relaciona à perda de competitividade externa, causada pela apreciação "virtual" no câmbio real, percebida na seção anterior 
(Gráfico 6) e ligada aos movimentos não coordenados de preços e salários entre os países-membros do Euro. ${ }^{5}$ A Alemanha, por exemplo, conteve aumentos de salário real nos últimos anos, enquanto na maioria dos países da Zona do Euro os salários aumentaram acima da inflação. Considerando a taxa de juros nominal comum entre os países, Lane (2006) afirma:

"Uma taxa de juros nominal comum implica que diferenças persistentes na inflação nacional se traduzam em diferenças nas taxas de juros reais entre os países-membros: países com inflação de médio prazo relativamente alta gozam de menores taxas de juros reais que aqueles com inflação média menor - estimulando demanda, crescimento do crédito e mercados de habitação no primeiro grupo. Ao longo do tempo, há um mecanismo corretivo compensatório, quando os países de inflação alta experimentam maiores custos de trabalho e outros, levando a uma perda de competitividade vis-à-vis o grupo de menor inflação da união monetária.” (Lane, 2006, p. 50)

Os dados empíricos corroboram a não validade do argumento de déficits gêmeos. É interessante notar pelo Gráfico 7 o cruzamento das curvas de saldo público e saldo em conta-corrente no exato momento da adoção do Euro. A partir daí, o saldo do setor público manteve-se controlado em quase todos os anos dentro do limite de $-3 \%$, enquanto houve deterioração do saldo externo. Percebe-se a baixa correlação existente entre um e outro. Em 2008 e 2009, mesmo com a forte expansão fiscal dos governos para minimizar os efeitos recessivos da crise do subprime, a posição externa não piorou, mostrando causalidade mínima ou nula entre os déficits público e externo. A Irlanda é o único país do grupo que segue tendência contrária - e por isso não foi incluída no Gráfico 7 - com déficit público acentuado (14,3\% do PIB para 2009) convivendo com superávit em conta-corrente também acentuado (17,2\% do PIB para 2009), fator, aliás, que corrobora a crítica ao argumento dos déficits gêmeos.

Jayme Jr. e Resende (2009) enfatizam a ligação das diferenças entre as taxas de crescimento econômico dos países e os graus distintos de restrição externa que eles enfrentam, relacionadas às dinâmicas de preços relativos e suas elasticidades e

\footnotetext{
${ }^{5}$ Bresser-Pereira (2010) critica a concepção de que a poupança externa seria positiva, pois se constituiria em aumento da taxa de investimento, e atesta que a primeira consequência para um país que tenta crescer com restrição externa é a apreciação cambial. "Mais amplamente, o endividamento externo provoca uma sucessão de três males: primeiro, temos uma elevada taxa de substituição da poupança interna pela externa, grande parte das entradas de capitais financiando o consumo ao invés do investimento; segundo, temos o aumento do endividamento externo que leva o país a uma condição de fragilidade externa e à política desastrosa do confidence building, a aceitar sem crítica as recomendações de credores e concorrentes; e, terceiro, temos a crise de balanço de pagamentos” (Bresser-Pereira, 2010).
} 


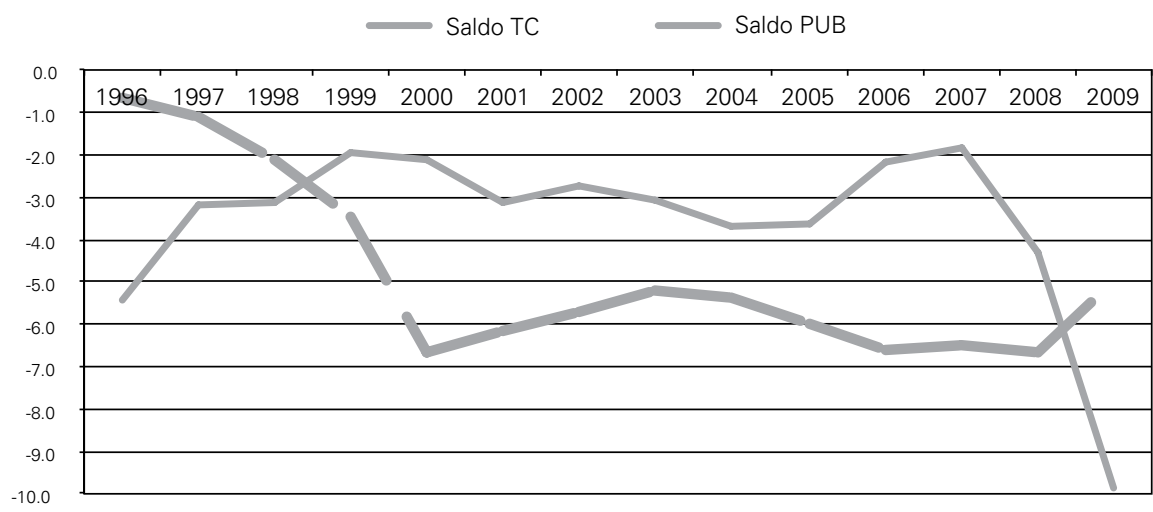

às diferentes estruturas industriais das nações. ${ }^{6}$ No caso da Zona do Euro, as diferentes estruturas industriais e tecnológicas agravam ainda mais as condições de competitividade entre os países, já fragilizadas pelos movimentos descompassados no câmbio real, impondo limitações sobre as possibilidades de melhora dos saldos de transações correntes.

Dois efeitos se desenham para essa limitação no campo das políticas econômicas agravada pelo contexto de restrição externa - e competitividade intrabloco - que atravessa os países centrais da presente análise. O primeiro efeito enfrentado pelos países menos desenvolvidos é então a dificuldade de ajustar a economia para a convergência inflacionária e fiscal europeia, sem que o país incorra em trajetória deflacionária e recessiva, uma vez que a contenção de gastos públicos deve ser disciplinada, o que tende a desaquecer a demanda interna. Reforça esse caráter recessivo a tentativa de controlar o déficit em transações correntes, através do controle orçamentário para aumentar a poupança pública. O segundo efeito é a desconfiança internacional quanto ao compromisso real dos governos grego, português, italiano e espanhol de promover esse ajuste fiscal, que afeta diretamente o prêmio de risco para ingresso de capitais nesses países, essenciais para o financiamento dos déficits externos.

A explosão da crise na Zona do Euro se deu exatamente quando esses dois efeitos se sobrepuseram. A recessão mundial de 2008 e 2009 atingiu fortemente os países europeus e a recuperação - ou a minimização da recessão - esteve diretamente ligada ao aumento significativo dos gastos públicos para aquecer a demanda. Quanto menor o poder de recuperação individual de um país, o que está diretamente ligado à sua estrutura produtiva e competitividade externa num momento de restrição de crédito e do comércio exterior, maior foi a dependência da demanda do governo para reduzir o efeito recessivo da crise mundial. Enquanto a Alema-

\footnotetext{
${ }^{6}$ Os autores fazem uma revisão das teorias cepalinas e kaldorianas, com ênfase nas elasticidades-renda de importação e exportação e na constituição de sistemas nacionais de inovação.
} 
nha já conseguiu se recuperar da crise - apresentando crescimento do produto superior a 3\% para 2010 sem grande aumento de déficit público - o que se observa na Grécia é a dificuldade de superação da recessão sem que o governo incorra em déficits progressivos (mesmo que o governo adote política fiscal austera dentro do limite de $3 \%$ de déficit, a dívida pública grega chegará a $150 \%$ do PIB nos próximos dois anos). $\mathrm{O}$ aumento do déficit e da dívida pública superaram os valores de referência, provocando temor de calote e necessidade de empréstimos da União Europeia e do FMI. Espanha, Portugal, Itália e Irlanda também passam por situação delicada em relação ao compromisso de suas dívidas. $\mathrm{O}$ ajuste que se desenha para a Grécia e para os outros casos é altamente recessivo e tem como base um ajuste fiscal duro, que tende a provocar escalada do desemprego, aumento dos impostos e corte de gastos relacionados a políticas sociais, com impacto direto sobre a população.

Desse modo, reitera-se que o problema principal da Zona do Euro repousa no modelo de união monetária concebido na Europa e seguido até então, que tendeu a aprofundar as divergências estruturais entre os países e, consequentemente, não permitiu um crescimento sustentado e convergente dos agregados macroeconômicos. Esse direcionamento se deu em função da priorização de políticas anti-inflacionárias que, alinhadas a teorias monetaristas e novo-clássicas, foram responsáveis por um modelo institucional conservador, o qual negligenciou a formulação de políticas comuns, que pudessem superar ou atenuar diferenças estruturais entre os países-membros, como a mencionada divergência de competitividade entre suas economias.

\section{CONSIDERAÇÕES FINAIS}

A crise das dívidas grega, portuguesa, espanhola e italiana expôs a fragilidade existente no modelo europeu para o desenvolvimento dos países-membros, que aprofundou em muitos pontos suas diferenças estruturais, contribuindo negativamente para o crescimento e o bem-estar social.

A União Europeia é sem dúvida um grande avanço em termos políticos e econômicos. Nunca se uniu tantos países democraticamente através de instituições comuns e, para alguns, uma moeda comum. É clara a importância do mercado comum europeu, que representa mais de $60 \%$ do comércio exterior para a maioria dos países-membros, além de permitir fluxos de capitais crescentes e mobilidade populacional, o que mostra um nível de complexidade institucional e ao mesmo tempo de simplificação burocrática sem precedentes, com grande impacto de redução de incertezas e custos de transação. Soma-se a isso a possibilidade de atuação coesa em bloco perante os órgãos mundiais, como a ONU e a OMC, no sentido de se desenvolver uma identidade europeia que preserve os interesses das nações envolvidas. Ademais, a União Europeia trouxe benefícios na forma de investimentos em infraestrutura nos países mais frágeis que nela entraram, subsidiados por impostos majoritariamente provenientes dos países mais ricos. Com efeito, a adesão 
à UE foi positiva em muitos aspectos, e significou uma mobilização em torno do desenvolvimento e da união a partir da identidade europeia.

No que se refere mais especificamente à Zona do Euro - e, consequentemente, ao debate estritamente econômico - o que se observa é a dificuldade de um consenso em torno da eficácia do Euro em promover o desenvolvimento e a convergência econômica entre os países que adotam a moeda. Os dados empíricos e a recente crise mostram que a UME está ainda longe de se configurar em uma Área Monetária Ótima nos moldes em que teorizaram os autores que primeiro discorreram sobre o tema.

Do ponto de vista teórico, vimos que, embora a mobilidade de capital tenha aumentado, com reflexos positivos de redução de custos de transação e incerteza, a mobilidade de mão de obra ainda é muito baixa, prejudicando o ajuste de desequilíbrios entre países através da realocação de fatores produtivos, como enfatiza a teoria. Além disso, os movimentos do câmbio real mostraram a incipiência dos ajustes de preços relativos entre os países, também para aliviar desequilíbrios de oferta e demanda entre eles. Assim sendo, o arcabouço teórico aparentemente não é corroborado pela realidade dos dados, restando somente uma possível comparação entre custos e benefícios que cada país individual teve com a adoção da moeda.

No que tange aos acontecimentos recentes da Zona do Euro, percebe-se uma fragilidade muito grande nas economias dos Estados menos desenvolvidos, principalmente no que se refere ao aspecto fiscal, à competitividade e à restrição externa. Era de esperar que a união monetária tendesse para a convergência dos ciclos econômicos dos países que dela fazem parte, através da superação de diferenças estruturais e de externalidades positivas e auxílio mútuo de uma economia em relação às outras. O que se observa, contudo, é a disparidade crescente de competitividade entre os países do bloco mais desenvolvido e os do bloco menos desenvolvido, com consequências dinâmicas perversas para os últimos. Como se viu, embora o câmbio nominal seja fixo, os movimentos divergentes de preços e salários relativos entre os países provocaram trajetórias totalmente distintas entre os câmbios reais. A valorização cambial e a impossibilidade de depreciação voluntária pressuposto da união monetária - geraram dependência externa crescente por parte dos países menos desenvolvidos, cuja estrutura industrial mais especializada dificulta ainda mais as possibilidades de recuperação dos saldos externos, com efeitos restritivos sobre o crescimento.

Esse cenário deixa os países muito mais vulneráveis a choques adversos, uma vez que a coordenação entre eles e a possibilidade de atuação de forma anticíclica no âmbito do bloco fica muito prejudicada, já que cada país segue trajetórias divergentes e demanda políticas específicas para cada período.

Foram criticados aqui dois pontos principais, que ao mesmo tempo servem como sugestão de políticas para a Zona do Euro: (i) o excessivo foco ortodoxo do modelo europeu; (ii) a insuficiência da integração política. Em relação ao primeiro ponto, entende-se excessivo o foco em controle de preços, que dá pouca margem para que os países tenham maior flexibilidade fiscal para realizar políticas anticíclicas. Esse fator gera desconfiança contínua quanto à capacidade dos governos 
dos países menos desenvolvidos - que dependem mais do Estado - de se manterem austeros e compromissados com o controle de suas dívidas públicas, o que eleva suas taxas de risco e o serviço das dívidas, dificultando seu pagamento. Por outro lado, exige taxas de juros maiores, que freiam o investimento, além de promoverem maior entrada de capitais de curto prazo nesses países, provocando pressões sobre o câmbio. $\mathrm{O}$ segundo ponto se refere à maior necessidade de coordenação política supranacional nas mãos das instituições europeias, concernentes a controles maiores sobre os ajustes de salários e preços relativos, para impedir que os países menos desenvolvidos percam progressivamente em competitividade. Adicionalmente, defende-se a criação de um orçamento comum europeu efetivo que sirva de auxílio para países que passem por recessões.

As implicações dessa discussão se estendem para a possível adesão de novos países à Zona do Euro e para o futuro da mesma. Para os próximos dois anos estão programadas as adesões de Estônia, Bulgária e Polônia à moeda comum. Diante do cenário descrito e da base econômica desses países, que se assemelha muito mais à de Portugal, Espanha e Grécia do que à de Alemanha, França e Áustria, surge a questão da viabilidade futura dessa área monetária. Se a evolução do modelo da UME deteriorou as posições competitivas dos países mais frágeis, bem como os colocou em grave recessão e crise orçamentária num contexto de crise mundial, com difíceis perspectivas de recuperação sem custos severos para a sociedade, o que podem esperar esses novos postulantes ao Euro? No mesmo sentido, a crise da dívida grega abalou as estruturas europeias e obrigou a oferta de um pacote de ajuda ao país, para evitar a perda de confiança dos mercados mundiais no Euro e consequências sobre toda a área.

Com efeito, é essencial um novo direcionamento das políticas supranacionais como forma de atenuar as perspectivas de desenvolvimento da Zona do Euro. $\mathrm{Na}$ ausência disso, os países-membros menos desenvolvidos — atuais e futuros - continuarão a se deparar com constantes ajustes recessivos, perdas de competitividade e consequências sociais, podendo motivar, inclusive, ameaças de abandono do Euro. Por outro lado, a Zona do Euro como um todo perderá credibilidade nos mercados mundiais, e a saída de membros poderá significar um retrocesso em uma trajetória que demorou décadas para se consolidar.

\section{REFERÊNCIAS BIBLIOGRÁFICAS}

BARRO, R.; GORDON, D. (1983). "Rules, discretion and reputation in a model of monetary policy", Journal of Monetary Economics, v. 12, p. 101-121.

BARBOSA-FILHO, Nelson H. (2001). "The balance-of-payments constraint: from balanced trade to sustainable debt”, Banca Nazionale del Lavoro Quarterly Review, v. 219, n. 54, p. 381-400.

BLECKER, R. (1992). Beyond the twin deficits: a trade strategy for the 1990s. New York: M. E. Sharpe.

BRESSER-PEREIRA, L. C. (2010). "Déficits, câmbio e crescimento", O Estado de São Paulo, 07/03/2010.

CARLIN, W.; SOSKICE, D. (2006). Macroeconomics: Imperfections, Institutions and Policies. Oxford: Oxford University Press. 
DE GRAUWE, P. (1997). The Economics of Monetary Integration, 3. ed. Oxford: Oxford University Press.

DE GRAUWE, P. (2009). “The fragility of the eurozone's institutions”, Open Economies Review, v. 21 n. 1, p. 167-174. Dordrecht: Springer Netherlands. Disponível em: <http://www.econ.kuleuven. be/ew/academic/intecon/Degrauwe/PDG-papers/Recently_published_articles/Fragility-eurozone-OER.pdf>. Acesso em: 17 jun. 2010.

DURANTE, D. S. (2002). "A unificação monetária europeia e seus impactos sobre o desemprego: uma abordagem pós-keynesiana”. Dissertação (Mestrado em Economia). CEDEPLAR, UFMG.

FERRARI FILHO, F.; ARESTIS, Philip; SAWYER, Malcolm; PAULA, Luiz Fernando de. (2003). "O euro e a UME: lições para o Mercosul”, Economia e Sociedade (Unicamp), v. 12, n. 1, p. 1-24.

FRIEDMAN, M. (1968). “The role of monetary policy”. American Economic Review, v.58, n.1, p.1-17.

JAYME JR., F. G.; RESENDE, M. F. C. (2009). "Crescimento econômico e restrição externa: teoria e a experiência brasileira”, in RENAULT Michel; MELLO Leonardo., orgs. Crescimento econômico: setor externo e inflação. 1 ed. Brasília: IPEA, v. 1, p. 25-45.

KENEN, P. B. (1969). "The theory of optimum currency areas: an eclectic view”, in MUNDELL, R. A., SWOBODA, A. K., orgs. Monetary problems of the international economy. Chicago: University of Chicago, p. 41-60.

KYDLAND, F.; PRESCOTT, E. (1977). "Rules rather than discretion: the inconsistency of optimal plans", Journal of Political Economy, 85.

LANE, Philip R. (2006). "The real effects of european monetary union”, Journal of Economic Perspectives," v. 20, p. 47-66.

MCKINNON, R. (1963). "Optimum currency areas”, American Economic Review, v. 53, n. 3, p. $717-$ -725 .

MORENO-BRID, Juan Carlos. (1998) "On capital flows and the balance-of-payments-constrained growth model”, Journal of Post Keynesian Economics, v. 21, n. 2, p. 283-298.

MUNDELL, R. (1961). "A theory of optimal currency areas”, American Economic Review, v. 51, p. 657-665.

RESENDE, M. F. C. (2009). "Déficits gêmeos e poupança nacional: abordagem teórica”, Revista de Economia Política, v. 29, n 1 (113), p. 24-42.

THIRLWALL, A.P.; HUSSAIN, M. Nureldin. (1982). "The balance of payments constraint, capital flows and growth rate differences between developing countries", Oxford Economic Papers, Oxford, v. 34, n. 3, p. 498-510. 